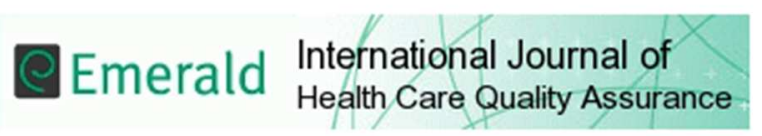

\title{
Improving Patient Safety in Libya: Insights from the British Health System
}

\begin{tabular}{|r|l|}
\hline Journal: & International Journal of Health Care Quality Assurance \\
\hline Manuscript ID & IJHCQA-09-2016-0133.R4 \\
\hline Manuscript Type: & Case Study \\
\hline Keywords: & $\begin{array}{l}\text { Patient safety, Policy, Quality healthcare, Risk Management, Training, } \\
\text { Governance }\end{array}$ \\
\hline \multicolumn{2}{|l}{} \\
\hline
\end{tabular}




\section{Improving patient safety in Libya: insights from a British health system perspective}

Author 1: Mustafa Elmontsri, BSc (Hons) MSc, PhD Student, Primary Care and Public Health, Imperial College London, London, United Kingdom, Telephone: 00442075943368, E-mail: m.elmontsri10@imperial.ac.uk

Author 2: Ahmed Almashrafi, MBA MSc PhD, Researcher, Primary Care and Public Health, Imperial College London, London, United Kingdom, Telephone: 00442075943368, E-mail: a.almashrafi@imperial.ac.uk

Author 3: Elizabeth Dubois, MSc MFPH FRSPH, Research Assistant, Primary Care and Public Health, Imperial College London, London, United Kingdom, Telephone: 00442075943389, E-mail: e.dubois@imperial.ac.uk

Author 4: Ricky Banarsee, PhD, Visiting Professor, Primary Care and Public Health, Imperial College London, London, United Kingdom, Telephone: 00442075940776, E-mail: r.banarsee@imperial.ac.uk

Author 5: Azeem Majeed, MD FRCP FRCGP FFPH, Professor of Primary Care and Pubic Health/Head of Department of Primary Care and Public Health, Primary Care and Public Health, Imperial College London, London, United Kingdom, Telephone: 0044207594 3368,E-mail: a.majeed@imperial.ac.uk

Corresponding author: Mustafa Elmontsri.

Corresponding Author's E-mail: m.elmontsri10@imperial.ac.uk

\section{Structured Abstract:}

Purpose: Patient safety's aim is to make healthcare safe for both patients and health professionals. Our purpose was to explore the UK's patient safety improvement programmes over the past 15 years and explore what lessons can be learnt to improve Libyan patient safety.

Approach: Publications focusing on UK patient safety were searched in academic databases and content analysed.

Findings: Several initiatives were undertaken over the past fifteen years to improve patient safety and the British health system. Many stakeholders are involved, including regulatory and professional bodies, educational providers and non-governmental organisations. Lessons can be learnt from the British journey.

Practical implications: Developing a national patient safety strategy for Libya, which reflects context and needs is paramount. Above all, Libyan patient safety programmes should reference internationally approved guidelines, evidence, policy and learning from Britain's unique experience.

Originality/value: This review examines patient safety improvement strategies adopted in Britain to help developing countries progress local strategies based on lessons learnt from Britain's unique experience.

Keywords: Patient safety; Healthcare; Libya; Incident reporting; Safety culture.

Article Classification: Literature review

Received $-14^{\text {th }}$ Oct 2016

Revised $-4^{\text {th }}$ March 2017

Accepted -

\section{Introduction}


Assessing variations in service quality was first considered in the early $20^{\text {th }}$ Century by Codman (Ballard et al., 2004). The healthcare safety epidemiology studies in the United States (US) (Brennan et al., 1991) and Australia (Wilson et al., 1995) shifted the focus on safer healthcare. In Western health services, studying safety failures suggests that one-in-ten people entering hospital experience an adverse event and one in 300 patients suffer serious consequences (Baker et al., 2004; Hogan et al., 2012; Zegers et al., 2009). Landrigan et al., (2010) suggested an even higher harm rate ( 25 per 100 admissions). Authors affirm that this rate hasn't changed over time. Consequently, a global patient safety movement was triggered by the Institute of Medicine's landmark report "To Err is Human: Building a Safer Health System" (Kohn et al., 2000). However, despite patient safety initiatives, harm to patients is still considered to be a reality in health services worldwide (Landrigan et al., 2010; Leistikow et al., 2011; Wachter, 2010).

Patient safety's core function is to prevent errors associated with healthcare and their mitigating effects (Vincent, 2010). In 2004, the World Health Organization (WHO) launched the World Alliance for Patient Safety programme to foster international collaboration and facilitate patient safety improvements worldwide (Donaldson and Fletcher, 2006). However, healthcare systems across the globe continue to experience avoidable patient harm. In England, 3.6\% of acute hospitals deaths are attributed to avoidable problems in care (Hogan et al., 2015). Even worse trends are present in the US. Makary and Daniel (2016) estimated that medical error is the third leading cause of death in the US. There are economic implications associated with poor care and adverse events. The Continuous Improvement Report, published by the United Kingdom's Health Foundation, for example, affirmed that unsafe care is expensive and that unreliable systems are unproductive, and costs can be reduced by providing safer care (Illingworth, 2015). Resources and unnecessarily high litigation costs lead to economic implications (Marshall and Øvretveit, 2011); e.g., costly, excessive hospital days in the United Kingdom (UK). Those attributed to patient injuries alone amounted to over $£ 1$ billion (Vincent et al., 2001).

\section{UK response to patient safety issues}

Several events and influences have contributed to emerging patient safety initiatives in the UK. In the 1970s and 1980s, audit, quality activities and litigation costs increased. Highprofile cases such as the Bristol paediatric cardiac surgery (Kennedy, 2001) and the Shipman inquiries (DoH, 2007) focused on healthcare safety and human error (Reason, 2000). Findings from major adverse events reviews (Brennan et al., 1991; Wilson et al., 1995) shifted the focus towards patient safety in the UK. In 2000, the UK's Chief Medical Officer (CMO) and Department of Health (DoH) published 'An organisation with a memory' report (DoH, 2000). This was the government's first report that set the scene for NHS patient safety improvements. The report indicated that 400 people in the UK die or are seriously injured from events related to medical devices each year. Additionally, adverse reactions to drugs and hospital-acquired infections cost the NHS over $£ 1$ billion per year. The NHS was described as having an old-fashioned approach to learning lessons from mistakes, so the report focused on shifting organisational culture, which inhibited reporting. A national, cohesive system that shares lessons learnt when things go wrong, was absent (DoH, 2000). 'Building a Safer NHS for Patients' is another report published by the DoH (2001) in response to the CMO's report and detailed specific plans, and timetable for promoting patient safety. Building local capacity, promoting a reporting culture and sustaining change through education, learning and performance assessment at both local and national levels were specific key areas targeted for action (DoH, 2001); e.g., aiming to reduce serious medical prescription errors by $40 \%$ by 2005 . A key change to improve patient safety was to establish 
the National Patient Safety Agency (NPSA) in 2001, which aimed to encourage reporting and learning from patient safety incidents and near misses.

Another UK stakeholder in patient safety management is the National Audit Office (NAO). The auditors published 'A Safer Place for Patients (Terry et al., 2005), which examined NHS performance regarding promoting a patient safety culture and encouraging reporting and learning from incidents. The report concluded that a more open and fair culture, created at a local level, and reporting has improved. The report notes the delays in establishing an effective national reporting system and that lessons aren't shared. Moreover, the first major patient safety improvement programme was known as 'The Safer Patients Initiative' (SPI), which was a large-scale intervention developed by Institute for Healthcare Improvement (IHI) staff (The Health Foundation, 2011). The first phase was launched in 2004 to improve patient safety across organisational levels. Health Foundation analysts reported that SPI has increased awareness of avoidable harm and helped to raise NHS patient safety profiles. Numerous patient safety campaigns and collaborations were launched across UK universities, the NHS and beyond as patient safety profiles increased (Burston et al., 2011; Slater et al., 2012). However, NHS patient safety issues remain an ongoing problem as reported by several UK inquiries such as the care provided at Mid Staffordshire NHS Trust (Francis, 2013), which reported that the hospital's culture focused on doing the system's business and not patient care. Among the issues identified were poor staffing levels, difficulties reporting mistakes and inefficient monitoring. The report also said that over 13 patients were killed or harmed every day in the NHS. From October 2014 to March 2015, there were 622,000 patient safety incidents recorded in general hospitals (acute, nonspecialist, NHS trusts) in England and Wales, of which 23,000 caused moderate or severe harm (NIHR, 2016).

\section{Patient safety governance and regulation}

Patient safety in the NHS is heavily regulated. Several bodies set standards and monitor organisations to ensure that their operations follow protocol. These regulatory bodies also enforce consequences on managers that do not meet standards. The Care Quality Commission (CQC), National Institute for Health and Care Excellence (NICE), Medicines and Healthcare Products Regulatory Agency and Monitor (now NHS Improvement) and the NHS Litigation Authority (previously known as National Clinical Assessment Service) are among the DoH's major arms-length bodies with regulatory roles (DoH, 2013). In addition to monitoring organisations, other government bodies are also responsible for regulating healthcare and specialised medical professionals to ensure compliance with standards. The Professionals Standards Authority for Health and Social Care (PSA) oversees statutory bodies that regulate health professionals. Different healthcare professions such as dentists, opticians and midwives are regulated by the PSA's separate bodies (nine regulatory bodies are overseen by the PSA), which conduct audits, monitor performance and report to the Parliament on serious issues. Organisations that hold health and social care occupation voluntary registers are also accredited against PSA standards. Fitness to Practice Schemes were introduced by these professional regulatory bodies to emphasise clinicians' individual patient safety responsibilities (Terry et al., 2005).

The CQC registers, monitors, inspects and regulates NHS and private healthcare services in England to ensure organisations meet fundamental quality and safety standards. It has the power to issue improvement notices and limit provider activities if services fall below minimum standards. The CQC ensures that patients are provided with safe, effective and high-quality care either in hospitals, care homes, dental and general practices, and other care services. Monitor, established in 2004, also had regulatory powers and works with the CQC and NHS England to ensure that patients receive high-quality care. In April 2016, Monitor 
was subsumed into NHS Improvement, which oversees NHS Trusts. Following the highprofile inquiry into the Mid Staffordshire NHS Foundation Trust, Francis (2013), concluded that the healthcare system requires more effective regulation and a culture, which shifted patient safety and quality improvement higher on the government's agenda. In response, the CQC developed five quality domains; safety, effectiveness, caring, responsiveness and wellled, which were used to rate healthcare providers. Patient safety governance and regulation in the UK is flexible and responsive to any lessons learnt from incident investigations and public inquires. The NHS Improvement's priority is to support providers and local health systems so that they can improve.

\section{Improving patient safety through education and training}

Education plays a key role in developing safe, high-quality health and nursing care (Francis, 2013; Mansour, 2012; Pearson et al., 2009; Slater et al., 2012; Wong et al., 2010). Health Education England (HEE) reported that patient safety education and training for undergraduates and apprentices alone is not sufficient to ensure patient safety improvements (Education and Training Comission for Patient Safety, 2016). Health Education England managers recognise that combining patient safety education and training with a learning culture within provider organisations, and a supportive system that enables workers to provide effective and safe care to patients is important. National Health Service professionals are provided with opportunities for learning and development throughout their careers; e.g., following Berwick's (2013) review into patient safety, the National Quality Board's (2013) (NQB) Human Factors in Healthcare concordat committed to including human factors, principles and practices in core education and training in NHS England.

Patient safety education in England is promoted and encouraged by many agencies including professional regulators. General Medical Council (GMC) and Nursing and Midwifery Council (NMC) officers collaborate with undergraduate and postgraduate education providers and the HEE to ensure that students are conversant with patient safety and quality improvement. A recent DoH report $(2015$, p.26) entitled 'Culture Change in the NHS' described medical students as the 'eyes and ears of the service today and the safety leaders of the future'. Health Education England officers established the Commission on Education and Training for Patient Safety, which recommends ways to improve awareness. Several English bodies recommend that patient safety education and training is integrated into the medical curriculum and staff development programmes. Training for nurses and midwives was designed by NPSA based on lessons learnt from other industries. The 'Safety First' report (DoH, 2006) recommended that the NHS Institute for Innovation and Improvement (now within NHS Improvement) should collaborate with all UK medical Royal Colleges and education providers to ensure that patient safety advances are incorporated into their curriculum.

The GMC has a statutory responsibility to set, maintain and promote undergraduate and postgraduate medical education standards including patient safety. The World Health Organization (2009) published a patient safety curriculum for medical schools, which was adopted by many UK educational providers to enhance patient safety education and training. Simulation-based training is being used to reduce errors and improve patient safety (Salas et al., 2005); e.g., the National Institute for Health Research Patient Safety Translational Research Centre at Imperial College London hosts a busy patient safety programme and offers a two-year Patient Safety Master's degree, training workshops and an annual symposium, which have been offered since 2007. One hundred students have been awarded the MSc in Quality and Safety (NIHR, 2016).

\section{Patient involvement in patient safety}


'Building a Safer NHS for Patients' (DoH, 2001) emphasised that patients need to be given a clear role in helping to promote and achieve patient safety goals. Patient and public involvement in safety was also promoted by the NPSA since its inception. Several campaigns and numerous leaflets, aiming to encourage and empower active patients, were introduced in the NHS over the past decade along with strict guidelines for healthcare staff on how to engage, communicate and involve patients or families following error or harm (NPSA, 2006, 2007, 2009). There is a widespread belief that patients can help to improve healthcare safety once they are involved (Davis et al., 2011; Hibbard et al., 2005). The NHS Constitution, which established NHS England's principles and values, makes it clear that patients must be told about any safety incident related to their care. The NHS Constitution clearly sets out patients' rights to an open and transparent relationship with their healthcare providers $(\mathrm{DoH}$, 2009a). Patient and public involvement in the UK is a key pillar in healthcare policy as it is a tool to improve services quality, which enhance accountability for public spending. The Department of Health (DoH, 2009b) report views patient and public involvement as an opportunity for patients to help design and deliver high-quality services. Patients in the UK are given the opportunity to participate in decision-making processes and having the opportunity to evaluate services and lodge complaints about healthcare providers, which should lead to an improved healthcare system (Longtin et al., 2010). Patients are also invited to present their experiences to board-level executives and within education to evaluate their satisfaction levels and their perspective on treatment clinical outcomes (Jha et al., 2014; Langer et al., 2016).

\section{Patient safety measurement and monitoring}

A key strategy adopted by UK NHS managers is learning from incidents; a method used for improving safety in industries such as aviation, and is being established in healthcare (Barach and Small, 2000; Forman and Goodman, 1990). Managers in the NHS are required by regulatory agencies to report incidents (Rooksby et al., 2007) and hospital incident reporting is a risk governance process (Benn et al., 2009). In 2003, the National Reporting and Learning System (NRLS) was established by NPSA officers, which requires hospital managers to report incidents. Currently, the agency receives over 1 million reports per year in England (Hutchinson et al., 2009), which are analysed and used for learning purposes to help NHS managers avoid incidents. Hospital risk management standards have been defined by the NHS Litigation Authority, which requires hospital managers to have a documented process for internal and external incidents and near misses (NHS Litigation Authority, 2012). Managers are required to report all incidences that occur within their premises to ensure lessons are learnt. Incident reporting schemes, developed in accordance with the host organisation, have technical and social components that are shaped to meet the organisation's needs (Balka et al., 2007), which is the case in the British system as these reporting systems are adapted to local needs. There are also other data used by NHS staff to measure and monitor patient safety performance, which has links to incident reporting, such as the annual NHS Staff Survey, which includes safety culture and incident reporting questions (Healthcare Commission, 2008). A rating is also awarded by the NHS Litigation Authority following a risk management assessment that is conducted within each hospital (NHS Litigation Authority, 2012). Traditionally, routine NHS information systems were mainly developed for management and administrative purposes, and not to help with measuring health status or healthcare outcomes (Majeed et al., 1994). There are different interventions used in the NHS to monitor patient safety, such as safety walk-rounds, which are used to visibly indicate senior manager commitment to safety that helps to establish a good safety culture (O'Dea and Flin, 2001). Risk registers are commonly used across healthcare settings in England, which are mandated by external regulators such as the NHS Litigation Authority. These local risk 
registers are updated regularly at divisional and departmental levels in which all risks are graded using a standard matrix. Risks with the highest scores are included in the trust's overall risk register (McILwain, 2006).

The Francis report made 209 recommendations that aim to change the corporate selfinterest culture and cost control associated with the Mid Staffordshire Foundation Trust failings. Various changes occurred in the NHS following the Francis report, which included creating Patient Safety Collaboratives that work with Academic Health Science Networks to support organisations and individuals to build safety improvement skills. A national campaign 'Sign Up to Safety' was also launched in 2014, which aims to reduce avoidable harm by $50 \%$ and save over 6,000 lives (Woodward and Director, 2015). The CQC's 2014/2015 State of Care report rated 13\% of hospitals as inadequate regarding patient safety and a further $61 \%$ requiring improvement (Care Quality Commission, 2015). Several reasons were cited for poor performance: failure to investigate and learn from patient safety incidents; staffing levels; training and support. Another intervention used to monitor patient safety performance is the NHS Safety Thermometer; a tool that allowed NHS managers to improve patient safety using a simple measuring tool; i.e., the Safety Thermometer included data from 6.6 million people, across 1,156 organisations in the 2015. Never Events, preventable patient safety incidents, such as wrong-site surgery and foreign object retention in a patient after surgical intervention, are also captured in the NHS Improvement programme. In April 2016, 28 serious incidents were reported, which implies weaknesses in how NHS staff manage fundamental safety processes (NHS Improvement, 2016). Hence, UK patient safety has become embedded in the healthcare professional dictionary, among policymakers, patients and the media. Several root causes were untangled, which led to specific interventions designed to be reduce patient harm. Research and intervention have become integral elements in policy prioritisation. It could be argued that UK healthcare professionals hold patient safety at the heart of what they do that led to improving patient outcomes.

\section{Patient safety in Libya: the way forward}

Libya's health system has suffered poor funding, neglect, inadequate development and modernisation (El Oakley et al., 2013). Libya's health services are provided free to all people. The country averages 37 hospital beds per 10,000 people, which is among highest number per person in Africa (WHO, 2010d2010b). Libyan healthcare quality deteriorated following the 2011 civil war (Daw et al., 2015). Distrust in Libya triggered a multimillion dollar medical tourism industry (Saleh et al., 2014).

Libya has a golden opportunity to strengthen its health system and improve healthcare quality, which depends on the country's ability to overcome, manage and resolve its ongoing conflict. Radical health system reform is required to ensure that health professionals offer high-quality, accessible primary and secondary care that meets Libyan population needs in the $21^{\text {st }}$ century (Majeed, 2013). The back-bone for advancing medical fields and improving healthcare services quality is medical and health service research (Rahman and Fukui, 2003). However, in developing countries, such as Libya, there is limited published medical research (Bakoush et al., 2007; Benamer et al., 2009). Studies estimating Libyan health system harm levels are not available, nor are there published studies that measure user satisfaction. There are several lessons that can be learned from the British patient safety experience. First, patient safety should evolve from health system changes. A continuous learning, monitoring and evaluation culture is vital to ensure that patients receive high-quality care. The UK's patient safety journey has been through continuous development. The cumulative knowledge about patient safety and public inquiries shifted the government's focus towards patient safety. The authors believe that the single most important milestone for Libya's health system is introducing regulation and standards. Governance and regulation institutionalises patient 
safety as a UK priority. Regulations that establish minimum standards for patient safety hold healthcare providers accountable and enable enforcement actions. Undoubtedly, healthcare is organised and financed in many ways across countries, but common interrelated challenges exist, which must be addressed by strategies that aim to improve patient safety. The vital step that should be taken by policy makers in Libya is to create an environment that is receptive to change at all Libyan health system levels. Key players and front-line staff should be involved in patient safety improvements including doctors, nurses, managers, administrators, policy makers, allied health professionals, patients and their families.

Second, regulations and standards alone are not enough as seen in the UK's context. Change requires robust and effective measurement. Setting priorities requires understanding and learning from harm to patients that results from current care systems (Small and Barach, 2002). Research studies that retrospectively reviewed patient healthcare records helped many countries generate knowledge about patient harm (Baker et al., 2004; Brennan et al., 1991; Vincent et al., 2001; Wilson et al., 1995). Reporting systems, such as NRLS, used in England, provided opportunities to learn lessons. It is vital that Libyan policy makers ensure that such reporting systems are not merely used for counting patient safety incidents, but rather focus on analysing these incidents to understand and identify factors that contribute to accidents, which helps to develop preventative strategies that aim to reduce patient risks based on risk management governance processes. There are other measurements that should be adopted, such as patient and staff surveys to measure satisfaction. Complaints analysis and direct observation should also be considered; i.e., measuring and monitoring healthcare services.

Third, it is also important to include patients and their families in quality and patient safety improvement processes. Health professionals in Libya need encouragement and policies should be put in place to ensure that patients are involved in care processes. The wider system will benefit from such policies that encourage patient participation as their concerns are vital to improving service quality. Currently, patient involvement is left to hospital managers as there is no nationally stipulated policy. Patients will be more empowered to voice their concerns about any issues that could lead to harm or diminish their satisfaction. Principally, patients must be treated with respect and dignity, and should be viewed as valued collaborators, which cannot be achieved without strict regulations, policies and procedures that encourage patient involvement. Patients in the UK have been empowered to shape policy development; i.e., being active participants as patient safety advocates while raising public awareness about patient safety issues. Adopting the NHS constitution could provide a path to patient's awareness about their roles, rights and responsibilities

Fourth, developed country medical education has been transformed over the last 40 years owing to medical environment changes. Medical education has shifted from traditional apprenticeship learning to simulations (Dall'Alba and Sandberg, 1996; Jain et al., 2015; McClurg et al., 2015). Libyan medical educational strategies and assessment methods require urgent updating to cope with healthcare delivery process changes (Benamer and Bakoush, 2009; Richardson et al., 2009; Sagher, 2006). The Libyan medical education curriculum has not been modernised (Richardson et al., 2009) and urgent policy decisions are needed, especially in funding provision, curriculum updates and promoting medical and health service research. Staff in many developed countries realised patient safety's importance in education and training. For Libya, patient safety education and training should be a core element in the national strategy for improving patient safety. These training and educational programmes should be based on best-practice. Three main dimensions should be considered when developing patient safety education and training programs: content, delivery and feedback. Libyan medical and nursing schools should benefit from the WHO Patient Safety Curriculum that is being adapted by many educational establishments around the globe including. 
Lessons should be learnt from the UK professional and regulatory agencies such as the GMC, which promotes undergraduate and postgraduate patient safety education. There are also no clear plans that clearly specifies human resources management processes within Libya's health sector. Accreditation systems and professional agencies are missing and there is no link between continuous medical education programs and career development in the country (WHO, 2010a), which has an ongoing significant impact on healthcare delivery and patient safety. Finally, a key priority identified in the WHO (2010a, p.44) strategy for developing Libyan health systems was 'developing a long-term national vision for health development and reforming and updating the health system', because there is limited information about Libyan health system performance (Chan et al., 2012). Information technology is critical for improving patient safety (Bates and Gawande, 2003). There are different bodies that regulate organisations, health professionals and specialist areas. There are also other regulatory agencies that control medications, medical equipment and supplies to ensure they all conform to standards. Electronic medical records have not been introduced to Libya's health system; e.g., using online prescribing methods to ensure patients are provided with the right medication to avoid errors owing to illegible doctor's handwriting or pharmacist's misunderstanding hand-written prescriptions. Libyan patient safety should be an integral element in the country's health system to ensure that patient trust is restored.

To ensure that management systems are efficient, patient safety should not be viewed as a leadership and management issue, but something that is dependent on systemic factors. Thus, doctor and patient involvement is crucial for successful patient safety initiatives. A system approach must be taken when redesigning the healthcare system for safer care (Akins and Cole, 2005). Medical errors are rooted in healthcare policy; e.g., Francis (2013) showed that interconnections and interdependence between healthcare professionals, who function under resource and performance pressures, are important, and lapses might occur. There also budget constraints that influence service quality and patent safety. Health system managers worldwide face financial constraints owing to global economic downturn (Tingle, 2016), which was also emphasised in the Francis report; i.e., low staffing levels. The approach adopted in response to constrained budgets is trying to do more with less, which will affect patient safety if not carefully planned ( $\mathrm{Yu}, 2016)$. Patient-care is also becoming increasingly complex owing to medical advances, which increases medical error risks. The UK and Libya systems are different in many aspects, including parliamentary roles and funding allocated to the healthcare sector. However, we believe that the Libyan healthcare system can benefit from the UK's rich patient safety experience. Given Libya's centralised healthcare system, implementing strategies that improve patient safety can be relatively easy. Libya could modernise its healthcare infrastructure, which will facilitate change.

\section{References}

Akins, R. B. and Cole, B. R. (2005), 'Barriers to implementation of patient safety systems in healthcare institutions: leadership and policy implications', Journal of Patient Safety, Vol. 1 No. 5, pp. 9-16.

Baker, G. R., Norton, P. G., Flintoft, V., Blais, R., Brown, A., Cox, J., Etchells, E., Ghali, W.A., Hébert, P., Majumdar, S.R. and O'Beirne, M. (2004), 'The Canadian Adverse Events Study: the incidence of adverse events among hospital patients in Canada', Canadian Medical Association Journal, Vol. 170 No. 11, pp. 1678-1686.

Bakoush, O., Al-Tubuly, A., Ashammakhi, N. and Elkhammas, E. (2007), 'PubMed medical publications from Libya', The Libyan Journal of Medicine, Vol. 2 No. 3, pp. 125128. 
Balka, E., Doyle-Waters, M., Lecznarowicz, D. and FitzGerald, J. M. (2007), 'Technology, governance and patient safety: Systems issues in technology and patient safety', International Journal of Medical Informatics, Vol. 76 No. 1, pp. 35-47

Ballard, D. J., Spreadbury, B. and Hopkins, R. S. (2004), 'Health care quality improvement across the Baylor Health Care System: the first century', Paper presented at the Baylor University Medical Center. Proceedings, Vol. 17 No. 3, pp. 277-288

Barach, P. and Small, S. D. (2000), 'Reporting and preventing medical mishaps: lessons from non-medical near miss reporting systems', British Medical Journal, Vol. 320 No. 7237, pp. 759-763.

Bates, D. W. and Gawande, A. A. (2003), 'Improving safety with information technology', New England Journal of Medicine, Vol. 348 No. 25, pp. 2526-2534.

Benamer, H., Bredan, A. and Bakoush, O. (2009), 'Scientific publication productivity of Libyan medical schools: a bibliometric study of papers listed in PubMed, 19882007', Education for Health, Vol. 22 No. 2, pp. 310-320.

Benamer, H. T. and Bakoush, O. (2009), 'Medical education in Libya: the challenges', Medical Teacher, Vol. 31 No. 6, pp. 493-496.

Benn, J., Burnett, S., Parand, A., Pinto, A., Iskander, S. and Vincent, C. (2009), 'Studying large-scale programmes to improve patient safety in whole care systems: challenges for research', Social Science and Medicine, Vol. 69 No. 12, pp. 1767-1776

Brennan, T. A., Leape, L. L., Laird, N. M., Hebert, L., Localio, A. R., Lawthers, A. G., Newhouse, J.P., Weiler, P.C. and Hiatt, H.H. (1991), 'Incidence of adverse events and negligence in hospitalized patients: results of the Harvard Medical Practice Study I', New England Journal of Medicine, Vol. 324 No. 6, pp. 370-376.

Burston, S., Chaboyer, W., Wallis, M. and Stanfield, J. (2011), 'A discussion of approaches to transforming care: contemporary strategies to improve patient safety', Journal of Advanced Nursing, Vol. 67 No. 11, pp. 2488-2495.

Care Quality Commission. (2015), 'State of Health Care and Adult Social Care in England 2014/15', <http://www.habiliscare.co.uk/images/docs/CQC_State_of_Care Report adult social care.pdf $>$, accessed July August 2016.

Chan, J. L., Colombo, R. and Musani, A. (2012), 'Mapping libyan health facilities-A collaboration between crisis mappers and the World Health Organization', Paper presented at the Proceedings of the Information Systems for Crisis Response and Management Conference (ISCRAM 2012).

Dall'Alba, G. and Sandberg, J. (1996), 'Educating for competence in professional practice', Instructional Science, Vol. 24 No. 6, pp. 411-437.

Davis, R., Sevdalis, N. and Vincent, C. (2011), 'Patient involvement in patient safety: How willing are patients to participate?', BMJ Quality \& Safety, Vol. 20 No. 1, pp. 108114.

Daw, M. A., El-Bouzedi, A. and Dau, A. A. (2015), 'Libyan armed conflict 2011: Mortality, injury and population displacement', African Journal of Emergency Medicine, Vol. 5 No. 3, pp. 101-107.

DoH. (2000), 'An organisation with a memory', <http://webarchive. nationalarchives.gov.uk/20130107105354/http://dh.gov.uk/en/publicationsandstatisti cs/publications/publicationspolicyandguidance/dh_4065083>, accessed August 2016.

DoH. (2001), 'Building a safer NHS for patients: implementing an organisation with a

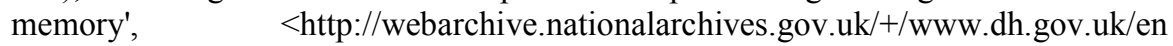
/Publicationsandstatistics/Publications/PublicationsPolicyAndGuidance/Browsable/ DH_4097460>, accessed August 2016. 
DoH. (2006), 'Safety First', <http://webarchive.nationalarchives.gov.uk/ 20130107105354/http:/www.dh.gov.uk/prod_consum_dh/groups/dh_digitalassets/@ $\mathrm{dh} / @$ en/documents/digitalasset/dh_064159.pdf $>$, accessed July $201 \overline{6}$.

DoH. (2007), 'Learning from tragedy, keeping patients safe. Overview of the Government's action programme in response to the recommendations of the Shipman Inquiry', $<$ https://www.gov.uk/government/uploads/system/uploads/attachment_data/file/228 88/6/7014.pdf $>$, accessed July 2016.

\section{DoH. (2009a), 'NHS Constitution', http://www.nhs.uk/NHSEngland/aboutnhs/Documents/NHS Constitution interactiv e 9Mar09.pdf $>$, accessed July 2016.}

DoH. (2009b), 'Helping the NHS put patients at the heart of care: the patient and public engagement support programme 2009-10', $<$ http://webarchive.nationalarchives.gov.uk/20130123200555/http://www.dh.gov.uk/ en/Publicationsandstatistics/Publications/PublicationsPolicyAndGuidance/DH_1060 46>, accessed June 2016.

DoH. (2013), 'Guide to the Healthcare System in England', $<$ https://www.gov.uk/government/

uploads/system/uploads/attachment_data/file/194002/9421-2900878-TSO NHSGuidetoHealthcareWEB.PDF>, accessed July 2016.

Donaldson, L. J. and Fletcher, M. G. (2006), 'The WHO World Alliance for Patient Safety: towards the years of living less dangerously', Medical Journal of Australia, Vol. 184 No. 10, pp. 69-72.

Education and Training Commission for Patient Safety. (2016), 'Improving Safety Through Education and Training', <https://hee.nhs.uk/sites/default/files/documents/ FULL\%20report\%20medium\%20res\%20for\%20web.pdf>, accessed June 2016.

El Oakley, R. M., Ghrew, M. H., Aboutwerat, A. A., Alageli, N. A., Neami, K. A., Kerwat, R. M., Elfituri, A.A., Ziglam, H.M., Saifenasser, A.M., Bahron, A.M. and Aburawi, E.H. (2013), 'Consultation on the Libyan health systems: towards patient-centred services', Libyan Journal of Medicine, Vol. 8 No. 1, pp. 1-9.

Forman, D. and Goodman, K. J. (1990), 'How the NHS can improve safety and learning', Cancer, Vol. 61, pp. 575-578.

Francis, R. (2013), 'Report of the Mid Staffordshire NHS Foundation Trust Public Inquiry: Executive Summary', Vol. 947, The Stationery Office, London.

Healthcare Commission. (2008), 'National NHS Staff Survey 2007', Healthcare Commission, London.

Hibbard, J. H., Peters, E., Slovic, P. and Tusler, M. (2005), 'Can patients be part of the solution? Views on their role in preventing medical errors', Medical Care Research and Review, Vol. 62 No. 5, pp. 601-616.

Hogan, H., Healey, F., Neale, G., Thomson, R., Vincent, C. and Black, N. (2012), 'Preventable deaths due to problems in care in English acute hospitals: a retrospective case record review study', BMJ Quality \& Safety, Vol. 21, pp. 737-745.

Hogan, H., Zipfel, R., Neuburger, J., Hutchings, A., Darzi, A. and Black, N. (2015), 'Avoidability of hospital deaths and association with hospital-wide mortality ratios: retrospective case record review and regression analysis', British Medical Journal, Vol. 351, pp. 1-6.h3239

Hutchinson, A., Young, T., Cooper, K., McIntosh, A., Karnon, J., Scobie, S. and Thomson, R. (2009), 'Trends in healthcare incident reporting and relationship to safety and quality data in acute hospitals: results from the National Reporting and Learning System', Quality and Safety in Health Care, Vol. 18 No. 1, pp, 5-10.
Comment [KH2]: Are the gaps meant to be underscored? URLs don't have gaps. Please address throughout.

Comment [EM3]: These underscores are within the URL itself. They were not added or changed by me. None of the underscores were added by me in any URL Thank you

Comment [KH4]: Please ensure that al titles have a closing quotation mark.

Comment [EM5]: I have checked again. Thank you

Comment [KH6]: 2016 is the most recent survey and is now published by NHS England.

Comment [EM7]: Thank you for this information. I have only mentioned the NHS staff survey to show the different performance measurement indicators that can be used by healthcare providers to improve their services.

Comment [KH8]: What does this letter mean? Is it a page number. Please address throughout.

Comment [EM9]: I have checked these again. BMJ usually cites its articles in this way as it is shown in the main article http://www.bmj.com/content/bmj/351/bmj.h 3239.full.pdf

I have corrected. Many thanks 
Illingworth, J. (2015), 'Continuous improvement of patient safety', < https://socialwelfare. bl.uk/subject-areas/services-activity/healthservices/healthfoundation/ 1765482015ContinuousImprovementPatientSafety.pdf $>$, accessed July 2016

Jain, C. C., Aiyer, M. K., Murphy, E., Alper, E. A., Durning, S., Aldag, J. and Torre, D. (2015), 'A National Assessment on Patient Safety Curricula in Undergraduate Medical Education: Results from the 2012 Clerkship Directors in Internal Medicine Survey', Journal of Patient Safety, Vol. 0, No. 0, pp. 1-5.

Jha, V., Buckley, H., Gabe, R., Kanaan, M., Lawton, R., Melville, C., Quinton, N., Symons, J., Thompson, Z., Watt, I. and Wright, J. (2014), 'Patients as teachers: a randomised controlled trial on the use of personal stories of harm to raise awareness of patient safety for doctors in training', British Medical JournalBMJ Quality \& Safety, Vol. 14, pp. 21-30.

Kennedy, I. (2001), 'Learning from Bristol: report of the public inquiry into children's heart surgery at Bristol Royal Infirmary 1984-1995', $\leq \mathrm{http}: / /$ webarchive. nationalarchives.gov.uk/20090811143745/http:/www.bristolinquiry.org.uk/final_rep ort/the_report.pdf $>$, accessed July 2016.

Kohn, L. T., Corrigan, J. M. and Donaldson, M. S. (2000), 'To err is human: building a safer health system', Committee on Quality Health Care in America, U.S. Institute of Medicine, National Academies Press, Washington, DC.

Landrigan, C. P., Parry, G. J., Bones, C. B., Hackbarth, A. D., Goldmann, D. A. and Sharek, P. J. (2010), 'Temporal trends in rates of patient harm resulting from medical care', New England Journal of Medicine, Vol. 363 No. 22, pp. 2124-2134.

Langer, T., Martinez, W., Browning, D. M., Varrin, P., Sarnoff Lee, B. and Bell, S. K. (2016), 'Patients and families as teachers: a mixed methods assessment of a collaborative learning model for medical error disclosure and prevention', British Medical Journal BMJ Quality \& Safety, Vol. 25 No. 8, pp. 615-625.

Leistikow, I. P., Kalkman, C. J. and de Bruijn, H. (2011), 'Why patient safety is such a tough nut to crack', British Medical Journal, Vol. 342, pp. 1-3d3447.

Longtin, Y., Sax, H., Leape, L. L., Sheridan, S. E., Donaldson, L. and Pittet, D. (2010), 'Patient participation: current knowledge and applicability to patient safety', Paper presented at the Mayo Clinic Proceedings, Vol. 85, No. 1, pp. 53-62

Majeed, A. (2013), 'General practice in the United Kingdom: meeting the challenges of the early 21st century', Journal of the Royal Society of Medicine, Vol. 106 No. 10, pp. 384-385.

Majeed, F. A., Chaturvedi, N., Reading, R. and Ben-Shlomo, Y. (1994), 'Equity in the NHS. Monitoring and promoting equity in primary and secondary care', British Medical Journal, Vol. 308 No. 6941, pp. 1426-1429.

Makary, M. A. and Daniel, M. (2016), 'Medical error - the third leading cause of death in the | US', British Medical Journal, Vol. 353, pp. 1-5i2139.

Mansour, M. (2012), 'Current assessment of patient safety education', British Journal of Nursing, Vol. 21 No. 9, pp. 536-543.

Marshall, M., and Øvretveit, J. (2011), 'Can we save money by improving quality?', British Medical Journal BMJ Quality and Safety, Vol. 20 No. 4, pp. 293-296.

McClurg, C., Powelson, S., Lang, E., Aghajafari, F. and Edworthy, S. (2015), 'Evaluating effectiveness of small group information literacy instruction for Undergraduate Medical Education students using a pre $\square$ and post $\square$ survey study design', Health Information \& Libraries Journal, Vol. 32 No. 2, pp. 120-130.

McILwain, J. C. (2006), 'A review: a decade of clinical risk management and risk tools', Clinician in Management, Vol. 14 No. 4, pp. 189-199.

Comment [KH10]: Is this correct.
Comment [EM11]: That is how it is being
cited in the main article as shown on this link
https://insights.ovid.com/pubmed?pmid=265
$\frac{58648}{\text { Thank you }}$
Comment [KH12]: Wrong title.
Comment [EM13]: Corrected. Thank you

Comment [KH14]: Is this a page number?

Comment [EM15]: This has been corrected as per article in this link

http://www.bmj.com/content/bmj/342/bmj.d 3447.full.pdf

. Thank you 
| NHS Improvement, U. (2016), 'Provisional publication of Never Events reported as occurring between 1 and 30 April 2016,' <https://improvement.nhs.uk/uploads/ documents/160526_NE_data_report_1-31_April_2016_DRAFT_v8_ed.pdf $>$, accessed August 2016 .

NHS Litigation Authority. (2012), 'NHSLA Risk Management Standards 2012-13 for NHS Trusts providing acute, community, or mental health \& learning disability services and non-NHS providers of NHS care', NHS Litigation Authority, London.

NIHR, A. (2016), 'A decade of improving patient safety', $<$ https://www1.imperial.ac.uk/resources/AF694C03-198B-4DBC-ADAC33369D54543B/pstrcbrochure.pdf $>$, accessed July 2016.

NPSA. (2006), 'Please Ask' campaign', <http://www.npsa.nhs.uk/pleaseask/>, accessed July 2016.

NPSA. (2007), 'Safety First: One Year On: Outlining progress on the recommendations of Safety $\quad$ First', <http://www.npsa.nhs.uk/EasySiteWeb/GatewayLink. aspx?alId=7026>, accessed July 2016.

NPSA. (2009), 'Being Open: Communicating Patient Safety Incidents with Patients and Carers', <http://www.nrls.npsa.nhs.uk/resources/?entryid45=65077>, accessed July 2016.

O'Dea, A. and Flin, R. (2001), 'Site managers and safety leadership in the offshore oil and gas industry', Safety Science, Vol. 37 No. 1, pp. 39-57.

Pearson, P., Steven, A. and Dawson, P. (2009), 'Patient safety in health care professional educational curricula: Examining the learning experience', $<$ http://www.birmingham.ac.uk/Documents/college-mds/haps/projects/cfhep/psrp/ finalreports/PS030PSRPReportFINAL0609.pdf>, accessed June 2016.

Rahman, M. and Fukui, T. (2003), 'Biomedical publication - global profile and trend', Public Health, Vol. 117 No. 4, pp. 274-280.

Reason, J. (2000), 'Human error: models and management', British Medical Journal, Vol. 320 No. 7237, pp. 768-770.

Richardson, J., Gill, D. and Woolf, K. (2009), 'Addressing Assessment in Libyan Medical Education', The Libyan Journal of Medicine, Vol. 4 No. 1, pp. 51-53.

Rooksby, J., Gerry, R. M. and Smith, A. F. (2007), 'Incident reporting schemes and the need for a good story', International Journal of Medical Informatics, Vol. 76, pp. 205211.

Sagher, F. (2006), 'What's wrong with medical education in Libya', Jamahiriya Medical Journal, Vol. 5, pp. 80-82.

Salas, E., Wilson, K. A., Burke, C. S. and Priest, H. A. (2005), 'Using simulation-based training to improve patient safety: what does it take?', The Joint Commission Journal on Quality and Patient Safety, Vol. 31 No. 7, pp. 363-371.

Saleh, S. S., Alameddine, M. S., Natafgi, N. M., Mataria, A., Sabri, B., Nasher, J., Zeiton, M., Ahmad, S. and Siddiqi, S. (2014), 'The path towards universal health coverage in the Arab uprising countries Tunisia, Egypt, Libya, and Yemen', The Lancet, Vol. 383 No. 9914, pp. 368-381.

Slater, B. L., Lawton, R., Armitage, G., Bibby, J. and Wright, J. (2012), 'Training and action for patient safety: embedding interprofessional education for patient safety within an improvement methodology', Journal of Continuing Education in the Health Professions, Vol. 32 No. 2, pp. 80-89.

Small, S. D. and Barach, P. (2002), 'Patient safety and health policy: a history and review', Hematology/Oncology Clinics of North America, Vol. 16 No. 6, pp. 1463-1482.

Terry, A., Mottram, C., Round, J., Firman, E., Step, J. and Bourne, J. (2005), 'A safer place for patients: learning to improve patient safety', The Stationery Office, London. 
The Health Foundation. (2011), 'Learning Report: Safer Patients Initiative, Lessons from the First Major Improvement Programme Addressing Patient Safety in the UK', London: The Health Foundation, <http://www.health.org.uk/sites/default/files/ SaferPatientsInitiative_LearningReport.pdf $>$, accessed July 2016.

Tingle, J. (2016), 'Patient safety: the next 15 years', British Journal of Nursing, Vol. 25 No. 9, pp. 518-519.

Vincent, C. (2010), Patient safety, Wiley-Blackwell, Chichester.

Vincent, C., Neale, G. and Woloshynowych, M. (2001), 'Adverse events in British hospitals: preliminary retrospective record review', British Medical Journal, Vol. 322 No. 7285 , pp. 517-519.

Wachter, R. M. (2010), 'Patient safety at ten: unmistakable progress, troubling gaps', Health Affairs, Vol. 29 No. 1, pp. 165-173.

WHO. (2009), 'WHO Patient Safety Curriculum Guide for Medical Schools', Geneva: WHO Press.

WHO. (2010a), 'Country Cooperation Strategy for WHO and Libya 2010-2015', Cairo, Egypt: WHO Press, <http://www.who.int/countryfocus/cooperation strategy/ccslbyen.pdf $>$, accessed July 2016.

WHO. (2010d2010b), 'Demographic, social and health indicators for countries of the Eastern Mediterranean', WHO Regional Office for the Eastern Mediterranean, Cairo, Egypt.

Wilson, R. M., Runciman, W. B., Gibberd, R. W., Harrison, B. T., Newby, L. and Hamilton, J. D. (1995), 'The quality in Australian health care study', Medical Journal of Australia, Vol. 163 No. 9, pp. 458-471.

Wong, B. M., Etchells, E. E., Kuper, A., Levinson, W. and Shojania, K. G. (2010), 'Teaching quality improvement and patient safety to trainees: a systematic review', Academic Medicine, Vol. 85 No. 9, pp. 1425-1439.

Woodward, S. and Director, C. (2015), 'Sign up to Safety', Nursing in Critical Care, Vol. 20 No. 4, pp. 172-173.

Yu, A., Flott, K., Chainani, N., Fontana, G. and Darzi, A. (2016), 'Patient Safety 2030', NIHR Imperial Patient Safety Translational Research Centre, $<$ http://www.imperial.ac.uk/media/imperial-college/institute-of-global-healthinnovation/centre-for-health-policy/Patient-Safety-2030-Report-VFinal.pdf>, accessed August 2016.

Zegers, M., De Bruijne, M., Wagner, C., Hoonhout, L., Waaijman, R., Smits, M., Hout, F.A.G., Zwaan, L., Christiaans-Dingelhoff, I., Timmermans, D.R.M. and Groenewegen, P.P. (2009), 'Adverse events and potentially preventable deaths in Dutch hospitals: results of a retrospective patient record review study', Quality and Safety in Health Care, Vol. 18 No. 4, pp. 297-302.
Comment [KH20]: Why jump from a to d? Please correct the mai text as well.

Comment [EM21]: This has been corrected here and in the main text.

Thank you 